\section{Controls in studies}

\section{of magnetism}

The appropriateness of controls is often neglected in systematic reviews of complementary therapies. In their systematic review and meta-analysis of static magnets for reducing pain, Max Pittler and colleagues correctly used the appropriateness of a trial's control as a criterion for including the trial in their analysis. ${ }^{1}$

However, for trials that used a weak magnet as their control, Pittler and colleagues failed to specify the maximal strength of the magnetic field that they felt was appropriate for controls, and they did not justify their choice with references to the published literature. They mentioned that it is assumed that magnets must have a strength of $30 \mathrm{mT}$ or greater for therapeutic benefit, but this value was cited from one of the reviewers' own articles and did not appear to be specific to the present study. Such information could be very useful for future studies in this area, especially given the authors' conclusion that "the ideal magnet strength and treatment duration are unclear." Assessing the trials the reviewers had excluded on the basis of the relative strengths of the placebo and test magnets might have had an impact on the outcomes reported.

\section{Peter W. McCarthy PhD}

Welsh Institute of Chiropractic, University of Glamorgan, Pontypridd, UK

Competing interests: None declared.

\section{REFERENCE}

I. Pittler MH, Brown EM, Ernst E. Static magnets for reducing pain: systematic review and meta-analysis of randomized trials. $C M A J 2007 ; 177: 736-42$.

DOI:I0.1503/cmaj.1070158

\section{[One of the authors responds:]}

We welcome Peter McCarthy's comments. As we reported in our article, the primary analysis in our study included only trials that compared magnets and a nonmagnetic placebo. ${ }^{1}$ There was no significant difference in pain reduction between the magnet and placebo groups as measured on a Ioo-mm visual analogue scale, which was defined as the primary outcome. The evidence does not support the use of static magnets for pain relief.

\section{Max H. Pittler MD PhD}

Deputy Director, Complementary

Medicine, Peninsula Medical School,

Universities of Exeter and Plymouth,

Exeter, UK

Competing interests: None declared.

\section{REFERENCE}

I. Pittler MH, Brown EM, Ernst E. Static magnets for reducing pain: systematic review and meta-analysis of randomized trials. $C M A J$ 2007;177:736-42.

DOI:Io.I503/cmaj.1070I63

\section{Combined antithrombotic}

\section{therapy}

The study by Joseph Delaney and colleagues on the use of antithrombotic medications raises many important questions. ${ }^{1}$ In several randomized controlled trials on coronary artery disease, giving oral anticoagulants to patients whose international normalized ratio was maintained between 2 and 3 did not significantly increase the risk of major bleeding. ${ }^{2}$ When added to antiplatelet therapy, oral anticoagulation therapy leads to a marginal but statistically significant reduction of cardiovascular risk. In patients who have atrial fibrillation, deep vein thrombosis or pulmonary embolism as well as coronary artery disease, the addition of acetylsalicylic acid to oral anticoagulation therapy is important because antiplatelet therapy has very little, if any, effect on the recurrence of deep vein thrombosis and pulmonary embolism and on stroke prevention, and warfarin has a minimal effect on the recurrence of coronary events.

The combination of acetylsalicylic acid and clopidogrel in the CURE trial did not lead to excess major bleeding, although there was some minor confounding with the use of glycoprotein IIb-IIIa inhibitors. ${ }^{3}$ In support of the authors' findings, the long-term addition of clopidogrel to acetylsalicylic acid in the CHARISMA trial was not beneficial in the population as a whole and did lead to some increase in bleeding. ${ }^{4}$ In patients with acute coronary syndrome and patients who have received a stent, however, dual antiplatelet therapy is crucial and the length of therapy depends upon the clinical setting and stent type. Trial data suggest that clopidogrel therapy should be limited to patients who would most benefit from it. It does not seem prudent to change this practice on the basis of the authors' findings.

The paper by Delaney and colleagues raises the very important question of the combined use of acetylsalicylic acid with nonsteroidal anti-inflammatory drugs. There appears to limited benefit to this drug combination and it should probably be avoided.

The authors imply that warfarin, acetylsalicylic acid and clopidogrel should not be used together because of the risk of gastrointestinal bleeding. Although their findings are certainly interesting, until further work elucidates the reasons for the increased bleeding risk their data should be interpreted with caution.

\section{David E. Good MD}

Fellow in Cardiovascular Medicine, Ochsner Clinic Foundation, New Orleans, La.

Competing interests: None declared.

\section{REFERENCES}

I. Delaney JA, Opatrny L, Brophy JM, et al. Drug-drug interactions between antithrombotic medications and the risk of gastrointestinal bleeding. CMAJ 2007;177:347-51.

2. Anand SS, Yusuf S. Oral anticoagulants in patients with coronary artery disease. J Am Coll Cardiol 2003;4I(4 Suppl S):62S-69S.

3. Yusuf S, Zhao F, Mehta SR, et al; Clopidogrel in Unstable Angina to Prevent Recurrent Events Tria Investigators. Effects of clopidogrel in addition to aspirin in patients with acute coronary syndromes without ST-segment elevation. $N$ Engl J Med 200I; 345:494-502.

4. Bhatt DL, Fox KAA, Hacke W, et al; CHARISMA Investigators. Clopidogrel and aspirin versus aspirin alone for the prevention of atherothrombotic events. N Engl J Med 2006;354:I706-I7.

DOI:I0.1503/cmaj.I070122

\section{[The authors respond:]}

We read with interest David Good's comments on our paper on drug-drug interactions between antithrombotic 
medications and the risk of gastrointestinal bleeding. ${ }^{1}$ We agree that many patients have an indication for therapy with a combination of antithrombotic drugs because of severe illness. In our paper we gave the specific example of co-prescribing warfarin and acetylsalicylic acid, which was associated with a decrease in complications after myocardial infarction. ${ }^{2}$

The goal of our paper was to elucidate and document the degree of increased risk experienced by patients who are prescribed these combinations of antithrombotic medications in a primary care setting. Although some clinical trials may not show an increased risk of gastrointestinal bleeding among patients whose international normalized ratio is tightly controlled, it is unclear how well such results will carry over into the primary care setting, where the use of combination therapy can reasonably be expected to be broader than in a clinical trial setting. Clinical trials tend to have restricted eligibility (they may exclude patients at very high risk for gastrointestinal bleeding) and tighter surveillance of parameters like the international normalized ratio. The increased risk of bleeding we saw in our study (which was conducted using the United Kingdom General Practice Research Database) was also shown in a recent meta-analysis of randomized controlled trials. ${ }^{3}$

Although one possible interpretation of our findings is that warfarin, clopidogrel and acetylsalicylic acid should not be prescribed in combination because of the risk of gastrointestinal bleeding, this was not the intended message of our paper. Our goal was to increase physician awareness of the magnitude of these drug-drug interac- tions; this goal was acknowledged in the thoughtful commentary that accompanied our article. ${ }^{4}$ We hope to promote informed choice on the part of both patients and physicians as they consider the risks and benefits of combining these therapies.

\section{Joseph A. Delaney PhD,} Lucie Opatrny MD MSc,

James M. Brophy MD PhD, Samy Suissa PhD Division of Clinical Epidemiology, McGill University Health Centre, Montréal, Que.

Competing interests: None declared for Joseph Delaney, Lucie Opatrny and James Brophy. Samy Suissa has served as an advisory board member for Pfizer and Bristol-Myers Squibb, and he has received consultancy fees from Bristol-Myers Squibb. Samy Suissa has received consultancy fees from Sanofi-Aventis for Lantus and leflunomide but not for clopidogrel.

\section{REFERENCES}

I. Delaney JA, Opatrny L, Brophy JM, et al. Drug-drug interactions between antithrombotic medications and the risk of gastrointestinal bleeding. CMAJ 2007; I77:347-5I.

2. Rothberg MB, Celestin C, Fiore LD, et al. Warfarin plus aspirin after myocardial infarction or the acute coronary syndrome: meta-analysis with estimates of risk and benefit. Ann Intern Med 2005;I43:24I-50.

3. Dentali F, Douketis JD, Lim W, et al. Combined aspirin-oral anticoagulant therapy compared with oral anticoagulant therapy alone among patients at risk for cardiovascular disease: a meta-analysis of randomized trials. Arch Intern Med 2007;167:117-24.

4. Juurlink DN. Drug interactions with warfarin: what clinicians need to know. CMAJ 2007;177:369-71.

DOI:Io.1503/cmaj.I070I32

\section{Letters submission process}

CMAJ's enhanced letters feature is now the portal for all submissions to our letters column. To prepare a letter, visit www.cmaj.ca and click "Submit a response to this article" in the box near the top right-hand corner of any CMAJ article. All letters will be considered for publication in the print journal.

Letters written in response to an article published in $C M A J$ are more likely to be accepted for print publication if they are submitted within 2 months of the article's publication date. Letters accepted for print publication are edited for length (usually 250 words) and house style.

\section{Mécanisme de présentation des lettres}

Le site amélioré des lettres du JAMC est désormais le portail de réception de tous les textes destinés à la chronique Lettres. Pour rédiger une lettre, consultez un article sur le site www.jamc.ca et cliquez ensuite sur le lien «Lettres électroniques : répondre à cet article», dans la boîte en haut à droite de l'article. Toutes les lettres seront étudiées pour une éventuelle publication dans le journal imprimé.

Les lettres répondant à un article publié dans le JAMC sont plus susceptibles d'être acceptées pour publication imprimée si elles sont présentées dans les deux mois de la date de publication de l'article. Les lettres acceptées pour publication imprimée sont révisées en fonction du style du JAMC et raccourcies au besoin (elles doivent habituellement compter au maximum 250 mots). 